\title{
Article
}

\section{Citation analysis of Canadian psycho- oncology and supportive care researchers}

Hack, Thomas, Crooks, Dauna, Plohman, James and Kepron, Emma Available at http://clok.uclan.ac.uk/13600/

Hack, Thomas, Crooks, Dauna, Plohman, James and Kepron, Emma (2014) Citation analysis of Canadian psycho-oncology and supportive care researchers. Supportive Care in Cancer, 22 (2). pp. 315-324. ISSN 0941-4355

It is advisable to refer to the publisher's version if you intend to cite from the work. http://dx.doi.org/10.1007/s00520-013-1966-5

For more information about UCLan's research in this area go to http://www.uclan.ac.uk/researchgroups/ and search for <name of research Group>.

For information about Research generally at UCLan please go to http://www.uclan.ac.uk/research/

All outputs in CLoK are protected by Intellectual Property Rights law, including Copyright law. Copyright, IPR and Moral Rights for the works on this site are retained by the individual authors and/or other copyright owners. Terms and conditions for use of this material are defined in the policies page.

\section{CLoK}

Central Lancashire online Knowledge www.clok.uclan.ac.uk

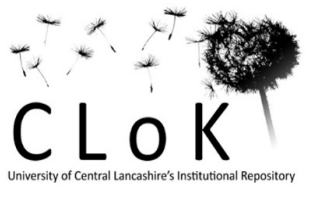


Running head: CITATION ANALYSIS

Citation Analysis of Canadian Psycho-Oncology and Supportive Care Researchers

Thomas F. Hack ${ }^{1,2} \quad$ Dauna Crooks $^{1} \quad$ James Plohman $^{1} \quad$ Emma Kepron ${ }^{1}$

${ }^{1}$ Faculty of Nursing, University of Manitoba, Winnipeg, MB, Canada; ${ }^{2}$ CancerCare Manitoba, Winnipeg, MB, Canada

Address correspondence and reprint requests to: Dr. Thomas Hack, Room CR3018, Asper Clinical Research Institute/St. Boniface Research Centre, 369 Taché Avenue, Winnipeg, Manitoba, Canada R2H 2A6 Ph: (204) 235-3791; Fax: (204) 233-7214; E-mail: thack@sbrc.ca. 


\begin{abstract}
Purpose: The purpose of this study was to conduct a historical review of psycho-oncology and supportive care research in Canada using citation analysis, and to review the clinical impact of the research conducted by the most highly cited researchers.

Methods: The lifetime journal publication records of 109 psycho-oncology and supportive care researchers in Canada were subject to citation analysis using the Scopus database, based on citations since 1996 of articles deemed relevant to psychosocial oncology and supportive care, excluding self-citations. Three primary types of analysis were performed for each individual: the number of citations for each journal publication, a summative citation count of all published articles, and the Scopus h-index.

Results: The top 20 psycho-oncology/supportive care researchers for each of five citation categories are presented: the number of citations for all publications; the number of citations for $1^{\text {st }}$-authored publications; the most highly cited $1^{\text {st }}$-authored publications; the Scopus hindex for all publications; and the Scopus h-index for $1^{\text {st }}$-authored publications. The three most highly cited Canadian psycho-oncology researchers are Dr. Kerry Courneya (University of Alberta), Dr. Lesley Degner, (University of Manitoba), and Dr. Harvey Chochinov (University of Manitoba).

Conclusions: Citation analysis is useful for examining the research performance of psychooncology and supportive care researchers and identifying leaders among them.
\end{abstract}

Key Words: Citation Analysis, h-index; Scopus, Psychosocial; Cancer; Oncology 
Citation Analysis of Canadian Psycho-Oncology and Supportive Care Researchers

Psycho-oncology research in Canada developed as a specialized branch of research in oncology in the 1970s. During this same time period, oncology centers began to employ professional staff to address the psychosocial well-being of cancer patients. The organization of psychosocial oncology services facilitated the growth of psycho-oncology research. Four decades later, psycho-oncology research is flourishing, thanks to the availability of general operating research dollars, as well as strategic research funding initiatives directed towards psycho-oncology and supportive care. In addition, there are several journals dedicated to the dissemination of psycho-oncology research findings.

In Canada, the Canadian Association of Psychosocial Oncology (CAPO) is the national association of health professionals joined in a mission to promote research, education and clinical practice in psychosocial oncology. The annual CAPO conference is a yearly showcase of the latest psycho-oncology research in Canada. The first CAPO conference was held in 1985, just a few years after the association was founded. There is now a large body of psychooncology research evidence to inform clinical practice, thanks in large part to the Canadian research pioneers in psycho-oncology who developed the field and whose mentoring efforts enabled psycho-oncology research to burgeon.

There is no standardized measure of research success. The standard means by which research findings are communicated to others is through a peer-reviewed journal publication. Research findings that are not published are less likely to reach a stakeholder audience. Consequently, desired clinical practice change is less likely or may be delayed if research findings are not published. Citation analysis is a valuable approach to determining the impact of an individual's published research, and is being used with greater frequency worldwide to 
inform tenure and promotion decisions. Citation analysis is an examination of the frequency with which an individual's journal publications have been cited by other researchers. The value of a researcher's publication is acknowledged when it is cited in the publication of another author. The collective value of a researcher's journal publications is indicated by his or her summative citation count. In 2005, Hirsch developed the highly-cited index (h-index), an indicator that goes beyond the cumulative publication count for an individual, and the cumulative citation count for an individual's body of publications, to consider in its calculation both the number of citations for each published work of an individual, and the number of publications that have received a given number of citations [1]. The h-index places a researcher's career into context, making it easier to compare and contrast the performance of groups of researchers. While there is debate surrounding the relative merit of the h-index when compared with alternative measures of scientific quality [2], it has been demonstrated that the h-index predicts future scientific achievement better than total citation count, citations per paper, and total publication count [3]. Citation analysis, particularly the h-index, has been used to examine the research publication success of nurse academics in Canada [4], professors of nursing in the UK [5], nurses in Australia [6], and breast cancer surgeons in the UK and Ireland [7]. The primary purpose of the present study was to conduct a historical review of psychooncology research in Canada using a citation analysis of the complete body of published research of Canadian psycho-oncology researchers and deemed relevant to psychosocial oncology and supportive care. The secondary purpose was to examine the clinical impact of the research conducted by the most highly cited researchers. The outputs of this analysis are tables presenting the most highly cited researchers according to total citation count and h- 
index, for all published articles and first-authored papers. In addition, the most highly cited research publications are presented.

\section{Methods}

The process of citation analysis began with the determination of the psychosocial oncology and supportive care researchers to be included in the analysis. The first step in this process was to review the current membership list of the Canadian Association of Psychosocial Oncology (CAPO) to identify individuals anticipated to place highly on one of the planned citation analysis lists. Seventy-two of 301 CAPO members were identified for inclusion. Only those individuals who currently reside and work in Canada were included; retired researchers were excluded. A further 37 individuals who are not CAPO members but are known to conduct psychosocial oncology or supportive care research, many of whom were known members of the Canadian Association of Nurses in Oncology (CANO), were added to this list, for a total of 109 individuals on whom the preliminary citation analysis was performed.

Given our interest only in citations to published papers specific to psychosocial oncology and supportive care in oncology, it was important to clearly define the scope of psychosocial oncology and supportive care for this analysis, and to develop eligibility criteria against which each published paper would be examined for inclusion in the citation analysis. The scope and practice of psychosocial (and supportive) oncology has broadened over the past several years, and researchers in related fields - chronic disease prevention, nutrition, patient navigation, rehabilitation - commonly find a home in psychosocial oncology. For the purpose of this study, psychosocial oncology was defined as "a specialty in cancer care concerned with understanding and treating the social, psychological, emotional, spiritual, quality-of-life and functional aspects of cancer, from prevention through bereavement. It is a whole-person 
approach to cancer care that addresses a range of very human needs that can improve quality of life for people affected by cancer.” [Canadian Association of Psychosocial Oncology website]. Supportive care was defined as "the provision of the necessary services for those living with or affected by cancer to meet their physical, emotional, psychological, informational, spiritual and practical needs during the diagnostic, treatment, and follow-up phases, encompassing issues of survivorship, palliative care and bereavement" [8, p.11]. These definitions were the starting point for the development of assumptions and decision rules, i.e., eligibility criteria, used to determine which papers were deemed relevant to psychosocial oncology and therefore included in the citation analysis.

The primary criterion for including a paper was that the paper must pertain to psychosocial oncology or supportive care in oncology or palliative care. Given our interest in oncology, palliative care studies with a patient sample consisting of $<50 \%$ cancer patients were excluded. For palliative care studies in which the disease of the sample was not provided, it was assumed that palliative samples are comprised of at least $50 \%$ cancer patients. Empirical and non-empirical works, e.g., review articles, meeting summaries, theoretical/conceptual writing, editorials, and “thought” pieces were included. For those papers that satisfied the primary criterion for inclusion, the following topic areas were included:

- Psychosocial and education/information needs and/or support of patients, including survivors, and caregivers

- Well-being of family/caregivers of cancer patients

- Treatment decision aids, medical decision making, treatment plans and outcomes 
- The quality of, or satisfaction with, cancer care

- Delivery of psychosocial and supportive care health services

- Support around the use of complementary and alternative therapies (CAT)

- Rehabilitation issues, e.g., exercise, diet, tobacco reduction

- Concerns or well-being of individuals without a diagnosis of cancer if the individuals in the sample are at high risk for cancer or perceive themselves to be at high risk for developing cancer

- Disease prevention efforts in individuals at high risk for cancer, and cancer risk prevention studies in the general population

- Development or psychometric validation of measurement tools

- Development or implementation of practice guidelines or establishment of research priorities

We excluded studies that addressed the well-being, work-related stress, or self-care efforts of health professional care-givers. In the absence of addressing a psychosocial or supportive care issue, the following types of studies were also excluded:

- Chronic disease prevention in the general or otherwise non high-risk for cancer population

- Physical symptom measurement or management

- Documentation of the prevalence and extent of CAT use

- Clinical drug treatment studies which include a psychosocial outcome(s), e.g., quality of life, but do not otherwise address psychosocial/supportive care issues of patients. 
The publication database Scopus, a database of citation counts since 1996, was used in this analysis. This source has the broadest coverage available of scientific, technical, medical and social sciences literature with approximately 18,500 peer reviewed journals covered. The author search utility of the Scopus website was used to search the names of each researcher, to produce a list of their respective publications, total citation counts of all publications, and Scopus h-index score. For the analysis of citation counts, all publications published in all years for each author were retrieved. To provide a truer, i.e., non-inflated, citation summary, the function to exclude the searched author's citations of their own publications was used in generating the total number of citations.

The h-index quantifies the cumulative impact and relevance of an individual's scientific research output. According to the h-index formula, a researcher has an index $\mathrm{h}$ if $\mathrm{h}$ of the total number of papers have at least h citations each, and the other papers (total number of papers h) have fewer than h citations each [1]. For example, assume that a researcher has 50 published journal articles. This researcher has an h-index of 10 if 10 of the 50 papers have at least 10 citations each, and the remaining 40 papers each have less than 10 citations. In short, the hindex is a count of the maximum number of publications that have each been cited an equal or greater number of times. To use a second example, if a researcher has a career total of 10 publications, and these 10 papers have been cited the following number of times $-5,1,6,10$, $4,12,0,1,5,8$ - then this researcher's h-index is 5: 5 papers have each been cited at least 5 times, and it is not the case that 6 papers have each been cited at least 6 times.

The Scopus h-index used in this study includes all publications from 1996 onwards. A manually calculated h-index that includes all documents in Scopus could also be calculated and 
would usually be higher in value, but for a fair comparison of authors, it is best to evaluate them over the same publication period; hence we reported the Scopus h-index.

In addition to generating the citation numbers and Scopus h-index for each author's publication list, $1^{\text {st }}$-authored publications were examined separately. To calculate the number of citations received for $1^{\text {st }}$-authored publications, all non- $1^{\text {st }}$-authored publications were selected and deleted from the list of publications to display the citation counts and h-index score of $1^{\text {st }}$-authored publications only.

Four top 30 lists were produced from the information gathered from the preliminary analyses: 1) Total citations for all publications; 2) Total citations for $1^{\text {st }}$-authored publications; 3) Scopus h-index for all publications; and 4) Scopus h-index for $1^{\text {st }}$-authored publications. Where ties existed in the h-index values of researchers, researchers were ordered in the list according to their cumulative number of citations for all publications or for $1^{\text {st }}$-authored publications.

The four top 30 lists were comprised of 49 individuals. The abstracts of all publications for these 49 individuals were reviewed for relevance to psychosocial oncology. In total, 3143 abstracts were reviewed for relevancy, resulting in the inclusion of 973 publications, the exclusion of 2046 publications, and 124 abstracts for which there was insufficient information to inform a decision to include or exclude. These 124 articles were retrieved and reviewed by two of the authors (TFH, DC) for relevance. This resulted in 1031 articles accepted for inclusion and 2112 articles excluded.

The review of abstracts produced an additional eight individuals for whom 361 abstracts were pulled, with 70 articles being accepted for inclusion and 290 being rejected. It was necessary to retrieve and review articles for one of these abstracts prior to deciding on whether 
or not to include the article in question. Two of these 8 individuals were dropped given that the majority of their citations were for publications generated while residents of the United States. This left 55 individuals to be studied in subsequent stages of the citation analysis. Prior to conducting further analyses, 7 psychosocial oncology research experts in Canada - representing nursing (Dr. Mary Jane Esplen, Dr. Marg Fitch, Ms. Esther Green), psychology (Dr. Zeev Rosberger), social work (Ms. Jill Taylor-Brown), psychiatry (Dr. Harvey Chochinov), and spiritual care (Dr. Shane Sinclair) - were sent the list of 55 individuals via email, informed of the purpose of the study, and asked to indicate whether, in their expert opinion, there was any individual missing from the list that might be expected to have sufficient citations to place in the top 30 of one or more of our planned citation lists. These psychosocial oncology leaders were also asked to comment on the validity of the decision rules for including/excluding articles for our planned analyses. Based on feedback from these experts, the decision rules were revised. In addition, the experts provided the names of 11 individuals to be added to our list of researchers, 8 of whom had been on our original search list of 109 researchers. The three other new names were each searched using SCOPUS, but their citation counts were too low to be considered further. A citation analysis was then repeated on September $6^{\text {th }}, 2011$ for the 55 outstanding individuals, generating five top 25 citation lists, including a list of the top 25 cited articles that was not produced in the initial citation analysis.

Although Scopus strives to ensure accuracy and completeness in their reporting of published research, it is possible that errors or omissions occur. For this reason, the top 25 individuals in each category of interest were sent an e-mail on November $4^{\text {th }}$, 2011 that explained the purpose of this study and requested an updated publication list so the research 
team could be confident that all of the relevant publications for each individual were included in the analysis. Twenty of these researchers submitted their publication lists via e-mail. This information confirmed that all relevant publications by these authors were included in the analysis and that no publications were mistakenly included in the analysis. The final lists of the top 20 individuals in each category were then generated. These lists present the total citation counts since 1996, excluding self-citations, and h-index values based on publications since 1996 excluding self-citations.

\section{Results}

Table 1a lists the top 20 Canadian psycho-oncology and supportive care researchers according to the number of citations since 1996, excluding self-citations, for all published journal articles deemed relevant to psychosocial oncology. The researcher with the highest number of citations is Dr. Kerry Courneya from the University of Alberta (3468 citations), followed closely in $2^{\text {nd }}$ place by Dr. Lesley Degner from the University of Manitoba (3452 career citations), with Dr. Harvey Chochinov from the University of Manitoba (2563 citations) in $3^{\text {rd }}$ place. Considering only $1^{\text {st }}$-authored journal articles (see Table $1 \mathrm{~b}$ ), the most highly cited researcher is Dr. Chochinov (1803 $1^{\text {st }}$-authored article citations), followed by Dr. Courneya and Dr. Degner. The difference between Tables 1a and 1b (and 3a and 3b below) is that Table 1a, by addressing all cited works, illustrates citation success for both independent investigator and co-investigator efforts, while Table $1 \mathrm{~b}$, citing only $1^{\text {st }}$-authored publications, demonstrates solely lead author citation accomplishment.

The 20 psychosocial oncology journal articles most highly cited since 1996 [9-29] that are $1^{\text {st }}$-authored by a Canadian psycho-oncology researcher are presented in Table 2. This table displays the important, perhaps seminal, psycho-oncology papers that have emerged from Canada. 
Dr. Degner maintains the $1^{\text {st }}$ and $2^{\text {nd }}$ positions on this list, with 537 and 448 citations, respectively, for two landmark articles on cancer patient involvement in treatment decision making. Dr. Pam Goodwin holds the $3^{\text {rd }}$ position with 363 citations to a paper examining the impact of group psychotherapy on survival in women with metastatic breast cancer. Dr. Degner has the distinction of holding four positions in the top 20. This list shows that an article cited at least 158 times since 1996 is in the top 20 of all cited journal articles ever written by Canadian psychooncology/supportive care researchers.

The top 20 researchers according to Scopus h-index are presented in Tables 3a (all articles) and 3b (only 1st-authored articles). Considering all journal articles deemed relevant to psychosocial oncology and published since 1996, the three researchers with the highest h-index are Dr. Courneya (h-index = 30), followed by Dr. Degner $($ h-index = 29) and Dr. Linda Carlson from Alberta Health Services (h-index $=24$ ). The top three researchers based on their h-index for $1^{\text {st }}$ authored publications are Dr. Courneya (h-index $=20$ ), Dr. Chochinov (h-index $=18$ ), and Dr. Carlson (h-index $=15)$.

The tables of results are consistently topped by four researchers - Drs. Carlson, Chochinov, Courneya and Degner. These four individuals collectively author 8 of the top 20 most highly cited journal articles presented in Table 2. Furthermore, their involvement as coauthors on these papers translates to a cumulative (co)authorship of 13 of these top cited papers. While this is an accomplishment of highest merit and distinction, it raises the question of whether the journal publications of these four researchers have contributed to clinical practice and policy beyond mere publication. In other words, have the career research contributions of these investigators made a significant contribution to improving clinical practice or policy in psychosocial oncology and supportive care? While it is difficult, if not 
seemingly impossible, to attribute clinical practice or policy change to a lone research paper, it can be argued that the collective published work of a researcher lacks value if it does not contribute to practice change. One would hope and expect, therefore, that the career efforts of these highly cited researchers would translate into meaningful practice change. The following discourse highlights the impact on clinical practice and/or policy made by each of these investigators.

Dr. Linda Carlson - Dr. Linda Carlson holds the Enbridge Research Chair in Psychosocial Oncology and directs the Integrative Oncology program at the Tom Baker Cancer Centre and the University of Calgary in Calgary, Canada. Dr. Carlson's clinical research into mindfulnessbased cancer recovery was the first published on the application of mindfulness for people with cancer, and has since informed the implementation and proliferation of mindfulness-based stress reduction programs in oncology throughout Canada and around the world. Her clinical discoveries through a series of qualitative, quantitative, and randomized controlled trials research are actualized in "how to" manuals for patients and professionals that have been distributed internationally, and she provides training workshops for professionals wishing to implement similar programs.

In Dr. Carlson’s other primary research area, Screening for Distress, the prevalence data and clinical trials her team published laid the foundation for the Canadian Partnership Against Cancer’s Screening for Distress Implementation program, which ran from 2009-2012 and resulted in program implementation in nine jurisdictions across Canada. Several provinces have since invested in permanent Screening for Distress programs, including Alberta which invested \$1 million in program funding for 2012-2013 alone. Additionally, over 40 agencies world-wide, including the National Comprehensive Cancer Network and most national psycho- 
oncology societies, have endorsed emotional distress as the " 6 th Vital Sign" in cancer care, and accreditation agencies in several countries now mandate its routine assessment.

Dr. Harvey Max Chochinov - Dr. Harvey Max Chochinov is the Director of the Manitoba Palliative Care Research Unit at CancerCare Manitoba and the University of Manitoba. Maintaining dignity for patients approaching death is a core principle of palliative care, and translating this principle into methods of guiding care at the end of life is the hallmark of Dr. Chochinov's research program. Successive studies conducted by Dr. Chochinov and colleagues have defined the construct of dignity from the perspective of dying cancer patients and defined core competencies of what has been coined dignity conserving care. He and his colleagues developed and tested the Personal Dignity Inventory measurement tool, and created and validated Dignity Therapy, a novel, brief, individual therapeutic intervention designed to address many of the psychological, existential, and spiritual challenges that patients and their families face as they grapple with the reality of life drawing to a close. Dignity Therapy has been studied in patients with advanced illnesses in Canada, the United States, Australia, China, Scotland, England, and Denmark. It has demonstrated benefits for patients as well as their families. As a result of Dr. Chochinov's groundbreaking research, Dignity Therapy is offered to palliative care patients in cancer centres, hospitals and hospices around the world. International training workshops on dignity therapy are offered annually, in Canada and abroad. Furthermore, Dr. Chochinov's research findings were presented at the Canadian federal government hearings on euthanasia and assisted suicide, and have spurred policy change in the form of revised core competencies and standards for end-of-life care. Dr. Kerry Courneya - Dr. Kerry Courneya is the Director of the Behavioral Medicine Laboratory at the University of Alberta in Edmonton, Canada. The goal of his lab is to 
generate new knowledge on how physical activity can help prevent cancer, mitigate the side effects of cancer treatments, enhance long term survivorship and quality of life, reduce the risk of disease recurrence, and improve survival. Dr. Courneya has conducted several large, randomized controlled trials to address these goals, and the results of these studies and those of his colleagues have been translated into practice in the form of structured exercise support programs for cancer survivors across Canada. Dr. Courneya has developed a state-of-the-art program of supervised exercise and behavioral support sessions designed to give people the tools they need to continue exercising on their own using their preferred mode of exercise. His research findings and exercise support programs have informed similar programs being offered to cancer survivors by the Young Men’s Christian Association (YMCA) in Canada.

Dr. Courneya’s research is exemplary in demonstrating impact on both policy and practice change. For instance, the American Cancer Society's physical activity and nutrition policy guidelines and the American College of Sports Medicine's exercise policy guidelines for cancer survivors cite his research extensively in making their recommendations. At one particular YMCA in Hamilton, Ontario, Canada, the pilot program was so successful in improving endurance and reducing fatigue, that the program is now a regular clinical offering. Cancer-related fatigue proves a useful example in placing Dr. Courneya’s work in historical context. Fatigue was first identified in 1998 as the most reported, severe and troublesome cancer-related symptom in Canadian women with breast cancer following a large survey of cancer patients [30]. Over a decade later, based on an empirical database informed by Dr. Courneya’s randomized controlled trial findings, systematic reviews of exercise interventions for women with breast cancer [31-32] report that cancer-related fatigue is reduced by exercise/physical rehabilitation, particularly supervised aerobic exercise. In addition, regular 
aerobic exercise is recommended in the Canadian practice guideline for the management of cancer-related fatigue [33]. Finally, Dr. Courneya’s research has contributed to the growing trend of the inclusion of physical activity information in patient education manuals and survivorship plans such as those developed by the Alberta Cancer Foundation, the British Columbia Cancer Agency, and the Canadian Cancer Society.

Dr Lesley Degner - Dr Lesley Degner is the founding Director of the Psychosocial Oncology and Cancer Nursing Research unit at the St. Boniface Hospital Research Centre and the University of Manitoba. Dr. Degner is known for her conceptualization of patient involvement in medical decision-making, illustrating how treatment decisions are made for patients with life-threatening cancer. Dr. Degner is among the first researchers to examine the core tenets of shared decision making, and her theoretical work resulted in the Control Preferences and Information Needs Scales - measurement tools which are employed internationally. Dr. Degner's research into information needs, decision-making preferences and the meaning of illness in women with breast cancer, have been replicated in several countries, including England, Sweden, USA, Greece and Japan. While Dr. Degner's research findings may not be so obviously associated with clinical practice or policy change, her pioneering revelations on the challenges and difficulties that patients face in trying to participate in medical decision making have influenced, arguably more than any other researcher, the shift from a paternalistic clinical practice style to one more reflective of consumerism and patient empowerment.

\section{Discussion}

The present findings demonstrate the degree of research recognition received by Canadian psycho-oncology and supportive care researchers, highlighting those researchers whose work is most often noted by other authors as having relevance and importance to their 
field of research. The researchers whose names appear in one or more of the tables in this article have demonstrated the value of their research findings to the broader international psycho-oncology and supportive care research community.

While it is our hope that the achievements of these highly cited individuals are recognized as such, and celebrated, there are other ways in which psycho-oncology and supportive care researchers make valuable contributions to the field that deserve mention. Many individuals, including some of those included in one or more of the results tables, have the distinction of having earned research chair awards, or some other career award. Others have served on research grant proposal review committees, while some have dedicated time to review manuscripts submitted for journal peer review. Many researchers have spent numerous hours providing learning opportunities to graduate students, or teaching in the classroom. Spending time on these research-related activities takes time away from conducting research and publishing research findings, yet these activities enhance the fields of psycho-oncology and supportive care and may lead, directly or indirectly, to research publications.

The present analysis reflects researchers' contributions to the fields of psychosocial oncology, not their total contributions to research. Citation analysis and the use of citation metrics like the h-index are a useful way to identify research publication leaders within a specified field such as psycho-oncology. The present citation results, however, are to be reviewed with the understanding that not all researchers within psycho-oncology and supportive care have an equal opportunity to conduct research. These fields of inquiry are populated with health professionals with workloads that vary with respect to time for research, teaching, and clinical service. Psychosocial clinicians with no affiliation to academic institutions may have little or no protected research time. Many clinicians are expected to 
squeeze research into their already full clinical work week. Those individuals with academic positions and an abundance of protected time for research are more likely to appear in the tables in this paper.

Citation count is a proxy for the value of a publication. As such, citation analysis does not capture the degree to which a published article shapes public health policy in oncology or influences psychosocial oncology or supportive care service delivery or education. It is for this reason that the citation analysis results reported herein were followed by an examination of the clinical practice changes and policy initiatives associated with the leading researchers identified in this analysis. Indeed, it is becoming increasingly common for research funding bodies to expect research applicants to detail plans to disseminate research findings to key stakeholders - agencies with the power and responsibility for health practice change, patient advocacy groups, and the general public. It is quite possible that an infrequently cited article might lead to improved psychosocial oncology service delivery and enhanced supportive care in oncology if dissemination efforts are successful. Positive efforts to translate the knowledge contained in a published empirical work toward the advancement of psychosocial care of cancer patients are not captured by citation counts alone.

While most of the $1^{\text {st }}$ authors of psycho-oncology and supportive care publications are responsible for the majority of the activities leading to the published work, a possible limitation of the $1^{\text {st }}$-authored publication lists in this paper is that well established researchers may have encouraged co-investigators to take the lead on publishing portions of their work, thereby reducing the number of first-authored papers for the established researcher.

Although citation analysis may require a painstaking effort to review abstracts and articles for applicability to a given field, such as psychosocial oncology, citation analysis is a 
meaningful tool for examining the publication success of individuals. Citation analysis is used as a criterion, along with publication count and journal impact factors, in tenure and promotion decisions. Psycho-oncology is a discipline approximately 40 years old, and there is a substantial empirical evidence base to support the variety of services and programs developed for the welfare of cancer patients and their families. It is our hope that the findings in this paper will be used to celebrate the history of psychosocial oncology and supportive care research in Canada, to facilitate its growth, and to bolster the careers of psycho-oncology and supportive care researchers. Other countries are encouraged to conduct similar citation analyses, to honor their psychosocial oncology leaders in this manner, to assess the contribution and impact their leading researchers have made on policy change and clinical practice in psychosocial and supportive care oncology, and to consider the implications of the current analysis on their efforts to build research capacity within their countries. 


\section{Acknowledgement}

Gratitude is extended to the Canadian Association of Psychosocial Oncology (CAPO) for providing access to their membership list.

\section{Conflict of Interest}

There are no conflicts of interest to declare. The authors have full control of all primary data and agree to allow the journal to review the data if requested. 


\section{References}

1. Hirsch JE (2005) An index to quantify an individual's scientific research output. P Natl Acad Sci USA 102(46):16569-16572. doi: 10.1073/pnas.0507655102

2. Lehmann S, Jackson AD, Lautrup BE (2006) Measure for measures. Nature 444(7122): 1003-1004. doi: 10.1038/4441003a

3. Hirsch JE (2007) Does the h index have predictive power? P Natl Acad Sci USA 104(49):19193-19198. doi: 10.1073/pnas.0707962104

4. Hack TF, Crooks D, Plohman J, Kepron E (2010) Research citation analysis of nursing academics in Canada: identifying success indicators. J Adv Nurs 66(11):2542-2549. doi: 10.1111/j.1365-2648.2010.05429.x

5. Thompson DR, Watson R (2010) Guest editorial: h-indices and the performance of professors of nursing in the UK. J Clin Nurs 19:2597-2958. doi: 10.1111/j.13652702.2010.03267.x

6. Hunt GE, Cleary M, Jackson D, Watson R, Thompson DR (2011) Editorial: citation analysis - focus on leading Australian nurse authors. J Clin Nurs 20:3273-3275. doi: 10.1111/j.1365-2702.2011.03917.x

7. Healy NA, Glynn RW, Scutaru C, Groneberg D, Kerin MJ, Sweeney KJ (2011) The h index and the identification of global benchmarks for breast cancer research output. Breast Cancer Res Tr 127:845-51. doi: 10.1007/s10549-011-1436-z

8. Fitch MI (2008) Supportive care framework. Can Oncol Nurs J 18(1):6-24

9. Degner LF, Kristjanson LJ, Bowman D, Sloan JA, Carriere KC, O’Neil J, Bilodeau B, Watson P, Mueller B (1997) Information needs and decisional preferences in women 
with breast cancer. J Amer Med Assoc 270(18):1485-1492. doi:

10.1001/jama.1997.03540420081039

10. Degner LF, Sloan JA (1992) Decision making during serious illness: What role do patients really want to play? J Clin Epidemiol 45(9):941-950.

doi: 10.1016/0895-4356(92)90110-9

11. Goodwin PJ, Leszcz M, Ennis M, Koopmans J, Vincent L, Guther H, Drysdale E, Hundleby M, Chochinov HM, Navarro M, Speca M, Masterson J, Dohan L, Sela R, Warren B, Paterson A, Pritchard KI, Arnold A, Doll R, O'Reilly SE, Quirt G, Hood N, Hunter J (2001) The effect of group psychosocial support on survival in metastatic breast cancer. New Engl J Med 345(24):1719-1726. doi: 10.1056/NEJMoa011871

12. Chochinov H, Wilson KG, Enns M, Mowchun N, Lander S, Levitt M, Clinch JJ. Desire for death in the terminally ill (1995) Am J Psychiat 152(8):1185-1191. doi: 10.1016/S1470-2045(11)70153-X

13. Speca M, Carlson LE, Goodey E, Angen M (2000) A randomized, wait-list controlled clinical trial: The effect of a mindfulness meditation-based stress reduction program on mood symptoms of stress in cancer outpatients. Psychosom Med 62(5):613-622.

14. Segal R, Evans W, Johnson D, Smith J, Colletta S, Gayton J, Woodard S, Wells G, Reid R (2001) Structured exercise improves physical functioning in women with stages I and II breast cancer: Results of a randomized controlled trial. J Clin Oncol 19(3):657-665.

15. Courneya KS, Mackey JR, Bell GJ, Jones LW, Field CJ, Fairey AS (2003) Randomized controlled trial of exercise training in postmenopausal breast cancer survivors: Cardiopulmonary and quality of life outcomes. J Clin Oncol 21(9):1660-1668. doi: 10.1200/JCO.2003.04.093 
16. Sutherland, HJ, Llewellyn-Thomas HA, Lockwood GA, Tritchler DL, Till JE (1989) Cancer patients: Their desire for information and participation in treatment decisions. J Roy Soc Med 82(5):260-263.

17. Segal RJ , Reid RD, Courneya KS, Malone SC, Parliament MB, Scott G, Venner PM, Quinney HA, Jones LW, D'Angelo MES, Wells GA (2003) Resistance exercise in men receiving androgen deprivation therapy for prostate cancer. J Clin Oncol 21(9):16531659. doi: 10.1200/JCO.2003.09.534

18. Chochinov HM, Wilson KG, Enns M, Lander S (1997) ‘Are you depressed?’ Screening for depression in the terminally ill. Am J Psychiat 154(5):674-676.

19. Maunsell E, Brisson J, Deschenes L (1993) Arm problems and psychological distress after surgery for breast cancer. Can J Surg 36(4):315-320.

20. McNeely ML, Campbell KL, Rowe B., Klassen TP, Mackey JR, Courneya KS (2006) Effects of exercise on breast cancer patients and survivors: A systematic review and meta-analysis. Can Med Assoc J 175(1):34-41. doi: 10.1503/cmaj.051073

21. Cohen SR, Mount BM, Strobel MG, Bui F (1995) The McGill Quality of Life Questionnaire: A measure of quality of life appropriate for people with advanced disease. A preliminary study of validity and acceptability. Palliative Med 9(3):207-219. doi: $10.1177 / 026921639500900306$

22. Hack TF, Degner LF, Dyck DG (1994) Relationship between preferences for decisional control and illness information among women with breast cancer: A quantitative and qualitative analysis. Soc Sci Med 39(2):279-289. doi: 10.1016/0277-9536(94)90336-0

23. Degner LF, Sloan JA, Venkatesh P. The Control Preferences Scale (1997) Can J Nurs Res 29(3):21-43. 
24. Dorval M, Maunsell E, Deschênes L, Brisson J, Mâsse B (1998) Long-term quality of life after breast cancer: Comparison of 8-year survivors with population controls. J Clin Oncol 1998; 16 (2): 487-494.

25. Irvine D, Brown B, Crooks D, Roberts J, Browne G (1991) Psychosocial adjustment in women with breast cancer. Cancer 1991; 67 (4): 1097-1117. doi: 10.1002/1097-0142(19910215)

26. Cohen SR, Mount BM, Bruera E, Provost M, Rowe J, Tong K (1997) Validity of the McGill Quality of Life Questionnaire in the palliative care setting: A multi-centre Canadian study demonstrating the importance of the existential domain. Palliative Med 1997; 11 (1): 3-20. doi: 10.1177/026921639701100102

27. Hack TF, Cohen L, Katz J, Robson LS, Goss P (1999) Physical and psychological morbidity after axillary lymph node dissection for breast cancer. J Clin Oncol 1999; 17 (1): $143-149$.

28. Degner LF, Sloan JA (1995) Symptom distress in newly diagnosed ambulatory cancer patients and as a predictor of survival in lung cancer. J Pain Symptom Manag 1995; 10 (6), 423-431. doi: 10.1016/0885-3924(95)00056-5

29. Carlson LE, Speca M, Patel KD, Goodey E (2003) Mindfulness-based stress reduction in relation to quality of life, mood, symptoms of stress, and immune parameters in breast and prostate cancer outpatients. Psychosom Med 2003; 65 (4), 571-581. doi: 10.1097/01.PSY.0000074003.35911.41

30. Ashbury FD, Findlay H, Reynolds B, McKerracher K (1998) A Canadian survey of cancer patients' experiences: are their needs being met? J Pain Symptom Manag 16(5):298-306. 
31. Egan MY, McEwen S, Sikora L, Chasen M, Fitch M, Eldred S (2013). Rehabilitation following cancer treatment. Disabil Rehabil. Advance online publication. doi: 10.3109/09638288.2013.774441

32. Velthuis MJ, Agasi-Idenburg SC, Aufdemkampe G, Wittink HM (2010). The effect of physical exercise on cancer-related fatigue during cancer treatment: a meta-analysis of randomized controlled trials Clin Oncol 22, 208-221. doi: 10.1016/j.clon.2009.12.005

33. Howell, D., Keller-Olaman, S., Oliver, T. K., Hack, T., Broadfield, L., Biggs, K., Chung, J., Esplen, M. J., Gravelle, D., Green, E., Hamel, M., Harth, T., Johnston, P., McLeod, M., Swinton, N., Syme, A., \& Olson, K. (February, 2011). A Pan-Canadian Practice Guideline: Screening, Assessment and Care of Cancer-Related Fatigue in Adults with Cancer. Toronto: Canadian Partnership Against Cancer (Cancer Journey Advisory Group) and the Canadian Association of Psychosocial Oncology. 


\section{Table 1a}

Top 20 Canadian Psycho-Oncology Researchers based on Citation Count since 1996, excluding Self-Citations, for all Journal Articles deemed relevant to Psychosocial Oncology

Name $\quad$ Affiliation $\quad$ Career Citations

1. Courneya, Kerry $\quad$ University of Alberta 3468

2. Degner, Lesley $\quad 3452$

3. Chochinov, Harvey University of Manitoba 2563

4. Carlson, Linda $\quad$ University of Calgary 2141

5. Speca, Michael Tom Baker Cancer Centre 1676

6. Maunsell, Elizabeth $\quad$ Laval University 1436

7. Hack, Thomas University of Manitoba 1423

8. Wilson, Keith $\quad$ University of Ottawa 1231

9. Friedenreich, Christine Alberta Cancer Board 1227

10. Fitch, Margaret $\quad 1225$

11. Gray, Ross Odette Cancer Centre 1084

12. Bultz, Barry University of Calgary 998

13. Cohen, Robin McGill University 813

14. Segal, Roanne Ottawa Regional Cancer Centre 785

15. Lockwood, Gina University of Toronto 774

16. Whelan, Tim McMaster University 742

17. Cunningham, Alistair Ontario Cancer Institute 690

18. McClement, Susan University of Manitoba 664

19. Goodwin, Pam University of Toronto 616

20. Doll, Richard British Columbia Cancer Agency 599 


\section{Table 1b}

Top 20 Canadian Top 20 Canadian Psycho-Oncology Researchers based on Citation Count, since 1996, excluding Self-Citations, for $1^{\text {st }}$-Authored Journal Articles deemed relevant to Psychosocial Oncology

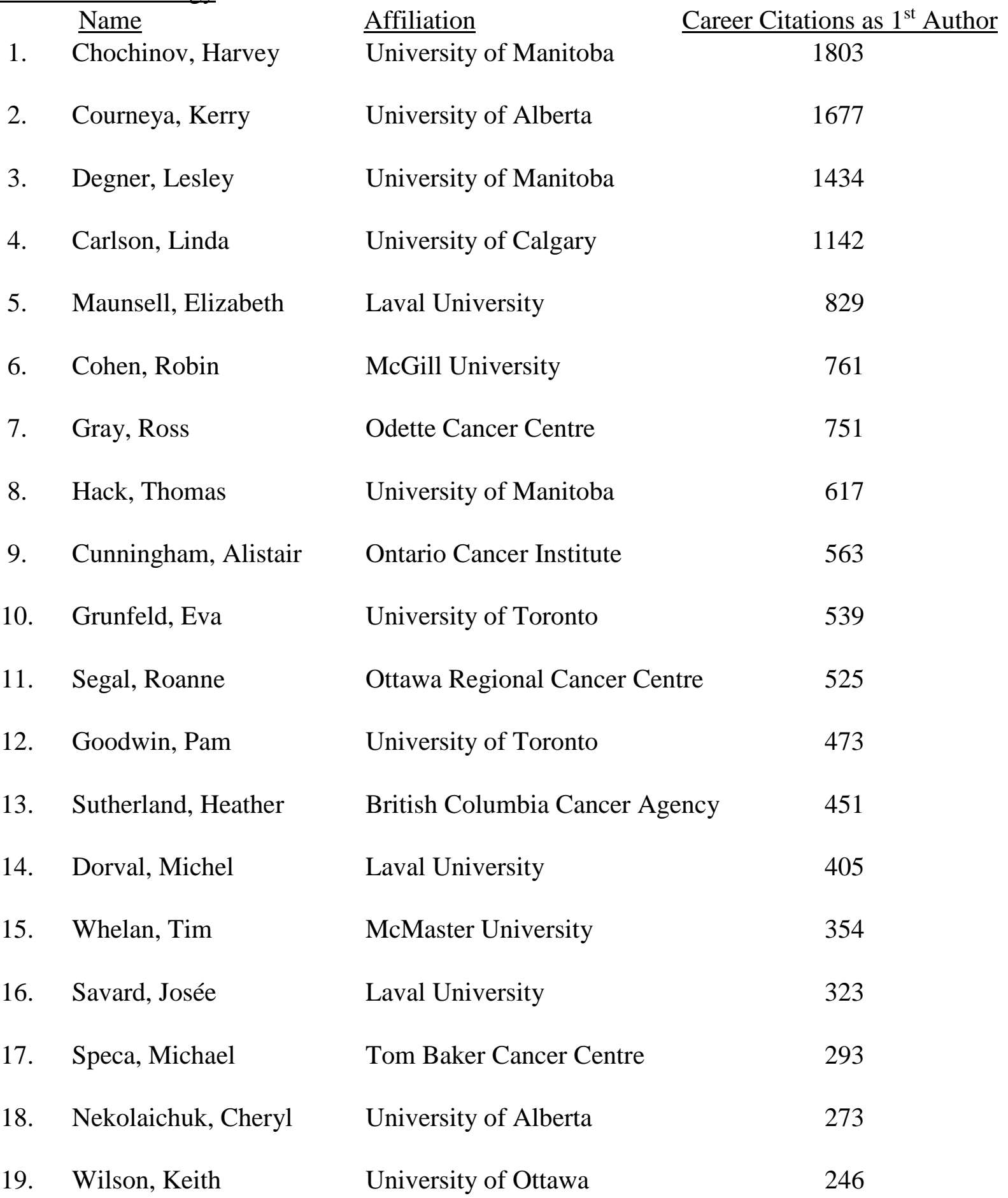


Citation Analysis 28

20. Woodgate, Roberta

University of Manitoba 


\section{Table 2}

Top 20 Most Highly Cited Journal Articles since 1996, excluding Self-Citations, deemed relevant to Psychosocial Oncology, and $1^{\text {st }}$-authored by Canadian Psycho-Oncology Researchers

\begin{tabular}{|c|c|c|c|}
\hline Name & Affiliation & Title (Year) & \# of Citations \\
\hline Degner, Lesley & $\begin{array}{c}\text { University of } \\
\text { Manitoba }\end{array}$ & $\begin{array}{l}\text { Information needs and } \\
\text { decisional preferences in } \\
\text { women with breast cancer } \\
\text { (1997) }\end{array}$ & 537 \\
\hline
\end{tabular}

2 Degner, Lesley $\begin{gathered}\text { University of } \\ \text { Manitoba }\end{gathered}$
Decision making during serious illness: What role do patients really want to play? (1992)

3 Goodwin, Pam

$$
\begin{aligned}
& \text { University of } \\
& \text { Toronto }
\end{aligned}
$$

The effect of group psychosocial support on survival in metastatic breast cancer (2001)

4 Chochinov, Harvey
University of Manitoba

Desire for death in the terminally ill (1995)

5 Speca, Michael

Tom Baker

A randomized, wait-listed controlled clinical trial: The effect of a mindfulness meditation-based stress reduction program on mood symptoms of stress in cancer outpatients (2000)

6 Segal, Roanne Ottawa Regional
Cancer Centre

Structured exercise improves physical functioning in women with stages I and II breast cancer: Results of a randomized controlled trial (2001)

$7 \quad$ Courneya, Kerry University of Randomized controlled trial of Alberta exercise training in postmenopausal breast cancer survivors: Cardiopulmonary and quality of life outcomes (2003) 
8 Sutherland,

British Cancer patients: Their desire

242

Heather

Columbia
Cancer Agency

for information and

Cancer Agency participation in treatment

decisions (1989)

$9 \quad$ Segal, Roanne

Ottawa Regional Resistance exercise in men

225

Cancer Centre

receiving androgen deprivation

therapy for prostate cancer

(2003)

10 Chochinov, Harvey

University of

'Are you depressed?'

223

Manitoba

Screening for depression in the terminally ill (1997)

11 Maunsell, Elizabeth

Laval University

Arm problems and

216

psychological distress after surgery for breast cancer (1993)

12 McNeely, Margaret

University of

Effects of exercise on breast

205 Alberta cancer patients and survivors: A systematic review and metaanalysis (2006)

13 Cohen, Robin

McGill

The McGill Quality of Life

202 University Questionnaire: A measure of quality of life appropriate for people with advanced disease. A preliminary study of validity and acceptability (1995)

14 Hack, Thomas

University of

Relationship between preferences for decisional control and illness information among women with breast cancer: A quantitative and qualitative analysis (1994)

15 Degner, Lesley

University of
Manitoba

The Control Preferences Scale (1997) 
breast cancer: Comparison of

8-year survivors with

population controls (1998)

17 Doran (Irvine),

McMaster

Psychosocial adjustment in

165 Diane

University

women with breast cancer (1991)

18 Cohen, Robin

McGill

Validity of the McGill Quality

163 University

of Life Questionnaire in the palliative care setting: A multicentre Canadian study demonstrating the importance of the existential domain (1997)

19 Hack, Thomas

University of

Physical and psychological morbidity after axillary lymph node dissection for breast cancer (1999)

20 Degner, Lesley

University of

Symptom distress in newly

158

(tie) Manitoba diagnosed ambulatory cancer patients and as a predictor of survival in lung cancer (1995)

20 Carlson, Linda

University of

Mindfulness-based stress stress, and immune parameters in breast and prostate cancer outpatients (2003) 


\section{Table 3a}

Top 20 Canadian Psycho-Oncology Researchers according to Scopus h-index for all Journal Article Citations since 1996, excluding Self-Citations, deemed relevant to Psychosocial Oncology

\begin{tabular}{|c|c|c|c|}
\hline & Name & $\underline{\text { Affiliation }}$ & $\underline{\text { h-index }}$ \\
\hline 1. & Courneya, Kerry & University of Alberta & 30 \\
\hline 2. & Degner, Lesley & University of Manitoba & 29 \\
\hline 3. & Carlson, Linda & University of Calgary & 24 \\
\hline 4. & Chochinov, Harvey & University of Manitoba & 23 \\
\hline 5. & Maunsell, Elizabeth & Laval University & 21 \\
\hline 6. & Fitch, Margaret & Odette Cancer Centre & 21 \\
\hline 7. & Hack, Thomas & University of Manitoba & 20 \\
\hline 8. & Gray, Ross & Odette Cancer Centre & 20 \\
\hline 9. & Bultz, Barry & University of Calgary & 18 \\
\hline 10. & Friedenreich, Christine & Alberta Cancer Board & 17 \\
\hline 11. & Speca, Michael & Tom Baker Cancer Centre & 15 \\
\hline 12. & Wilson, Keith & University of Ottawa & 14 \\
\hline 13. & Cunningham, Alistair & Ontario Cancer Institute & 14 \\
\hline 14. & McClement, Susan & University of Manitoba & 14 \\
\hline 15. & Woodgate, Roberta & University of Manitoba & 14 \\
\hline 16. & Savard, Josée & Laval University & 13 \\
\hline 17. & Devins, Gerald & University of Toronto & 13 \\
\hline 18. & Rodin, Gary & University of Toronto & 13 \\
\hline 19. & Whelan, Tim & McMaster University & 12 \\
\hline
\end{tabular}


Citation Analysis 33

20. Harlos, Michael University of Manitoba 


\section{Table 3b}

Top 20 Canadian Psycho-Oncology Researchers according to Scopus h-index for $1^{\text {st }}$-Authored Journal Article Citations since 1996, excluding Self-Citations, deemed relevant to Psychosocial Oncology

Name

1. Courneya, Kerry

2. Chochinov, Harvey

3. Carlson, Linda

4. Gray, Ross

5. Cunningham, Alistair

6. Maunsell, Elizabeth

7. Woodgate, Roberta

8. Fitch, Margaret

9. Cohen, Robin

10. Hack, Thomas

11. Degner, Lesley

12. Thorne, Sally

13. McClement, Susan

14. Nekolaichuk, Cheryl

15. Allison, Paul

16. Feldman-Stewart, Deb

17. Bottorff, Joan

18. Grunfeld, Eva

19. Goodwin, Pam

20. Sutherland, Heather $\underline{\text { Affiliation }}$

University of Alberta

University of Manitoba

University of Calgary

Odette Cancer Centre

Ontario Cancer Institute

Laval University

University of Manitoba

Odette Cancer Centre

McGill University

University of Manitoba

University of Manitoba

University of British Columbia

University of Manitoba

University of Alberta

McGill University

Queens University

University of British Columbia

University of Toronto

University of Toronto

British Columbia Cancer Agency $\underline{\text { h-index }}$

20

18

15

14

12

11

11

10

9

9

8

8

8

7

7

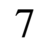

7

6

6

6 
Citation Analysis 35 